\title{
Could Hormone Remission be Achieved in Prolactinomas with Surgery?
}

\author{
Palamar 0*, Huk A, Aksyonov R, Okonskyi D andTeslenko D \\ Department of endoscopic and craniofacial neurosurgery, Romodanov Neurosurgery Institute, Ukraine
}

Submission: May 24 2018; Published: July 18, 2018

*Corresponding author: Palamar 0, Department of endoscopic and craniofacial neurosurgery, Romodanov Neurosurgery Institute, Kiev, Ukraine; Tel: +38-(044)-4831428; +38-(050)-4194364; Email: p_orest@ukr.net

Abstract

We retrospectively analyzed 33 prolactinomacases. Endoscopic endonasal transsphenoidal (EET) surgery can be used as an effective method for microprolactinomastreatment to achieve rapid biochemical and clinical remission. In some macroprolactinomas $(<24 \mathrm{~mm})$ EET surgery is effective $(90 \%$ cases)

Keywords: Pituitary adenoma;Prolactinoma;Endoscopic endonasal transsphenoidal surgery;Biochemical remission

\section{Introduction}

Dopamine agonists (DA) are recognized as an effective medical treatmentsince the beginning $1970 \mathrm{~s}\left[{ }^{1,2}\right]$ Normoprolactinemia was achievedin 59\%when using bromocriptine $\left[{ }^{3}\right]$.Normal PRL level can be achieved in 80-90\%when using DA. Relevant systemic side effects, including vomiting, nausea, dizziness, headache have been reported in about one third of patients treated with DAs[ ${ }^{4,5}$. DAs have a significant effect on other dopamine, serotonin androgenic receptors, which leads to severe neurological disorders such as postural hypotension or dyskinesia, psychosis, or mania, which provoke compulsive states[6,7]. In some cases these possible complications assume surgery over prolactinomas.

\section{Material and Methods}

This study included 33 patients who underwent primary pituitary surgery over prolactinomas with no prior DA treatment
(19 female, 14 male; age ranged, 20-67 years). Microprolactinomas10 cases, macroprolactinomas 19 cases, giant prolactinoma 4 cases.endoscopic endonasal transsphenoidal (EET) surgery was performed by single neurosurgeon. Plasma PRL levels were obtained before surgery, and then on the $1^{\text {st }}$ day, $1^{\text {st }}$ week, $1^{\text {st }}$ month, $3^{\text {rd }}$ month and then every $6^{\text {th }}$ months after surgery. Catamnesis1-5 yearsMRI check-up was performed before surgery and then on 3, 6 and 12month, then on yearly basis.

\section{Results and Discussion}

Median preop PRL serum level for all patients was530ng/ $\mathrm{mL}$ (ranging, 65-1440ng/mL)Cavernous sinus invasion was ob served in $16(48,5 \%)$ cases after surgery. Biochemical remission of PRL level back to normal wasin 10 cases withmicroprolactinomas (100\%), in 10 (53\%) cases of macroprolactinomas after surgery.No DA therapy after surgery in those with normal PRL

\footnotetext{
${ }^{1}$ Thorner MO, McNeilly AS, Hagan C \& Besser GM. Long-term treatment of galactorrhoea and hypogonadism with bromocrip- tine. BMJ 19742 419-422. ${ }^{2}$ Werder K, Fahlbusch R, Landgraf R, Pickardt CR, Rjosk HK \& Scriba PC. Treatment of patients with prolactinomas. Journal of Endocrinological Investigation 19781 47-58
}

${ }^{3}$ WebsterJ,PiscitelliG,PolliA,FerrariCl,IsmailI\&ScanlonMF.For the Cabergoline Comparative Study Group. New England Journal of Medicine, 1994 904-909

${ }^{4}$ Molitch ME (1999) Medical treatment of prolactinomas. Endo- crinolMetab Clin North Am 28(1):143-169

${ }^{5}$ Diagnosis and treatment of hyperprolactinemia: An endocrine society clinical practice guideline, 2011

${ }^{6} 14$.Noronha S, Stokes V, Karavitaki N \& Grossman A. 2010. Treating prolactinomas with dopamine agonists: always worth the gamble?.Endocrine In press 10.1007/s12020-015-0727-2

${ }^{7}$ 16.Ali S, Klahr K \&Freudenreich 0. 2015. Management of psychosis associated with a prolactinoma: case and review of the literature. Psychosomatics 51 2010. 370-376. 10.1016/S0033-3182(10)70718-0. 


\section{Journal of Endocrinology and Thyroid Research}

serum level. Follow up lasted1-5 years. Postoperative complications such as CSF leak, meningitis, additional oculomotor disorder or visual impairment have not been established. No mortality.Biochemical and clinical remission was achieved after EET surgery with no DA therapy: microadenomas - $100 \%$ cases, macroprolactinomas-53\% (macroprolactinomas with size less then $24 \mathrm{~mm}-90 \%$ cases). Visual disturbances and visual field defects improved in all cases over macro and giant prolactinomas.

EET surgery overmicro and macroprolactinomas (tumor should be removed in capsule) achievesbiochemical and clinical remission within a short period of time. Though EET surgery over microprolactinomas gives $100 \%$ remission rate, in cases of macroprolactinomas EET surgery gives 53\% remission rate. Macroadenomas give recurrence after surgery in 6 months period. We noticed that the size starting from $24 \mathrm{~mm}$ and more would likely to lead to recurrence. Meanwhile macroprolactinomas less then 24 mmgive $90 \%$ remission. Cavernous sinus invasion is predicting factor over recurrence.

\section{Conclusion}

Biochemical remission could be achieved surgically especially in microprolactinomas in $100 \%$ cases.

Biochemical remission might be achieved surgically in macroprolactinomas with size less then $24 \mathrm{~mm}$ ( $90 \%$ cases), cavernous sinus invasion (Knosp 0-2) is the prognostic factor.Ophthalmic symptoms regression is achieved in $100 \%$ patients and faster in cases macro and giant adenoma in comparison to DA therapy. Menses normalized in $100 \%$ cases of microprolactinomas and in $86 \%$ cases in macroadenomas with size less then $24 \mathrm{~mm}$.
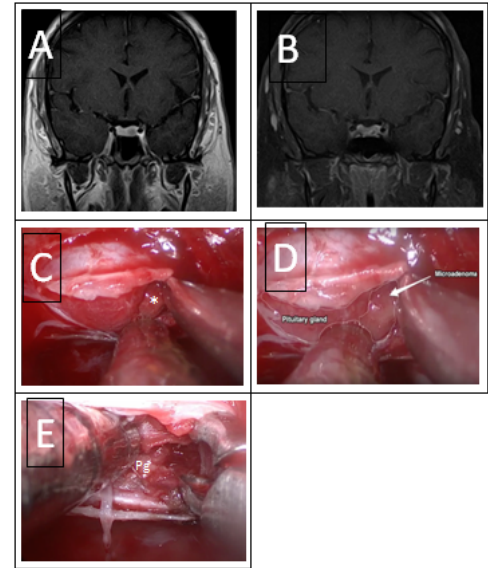

Case 1: Women 30 y.o. presenting with amenorrhea, galactorrhea. Preoperative T1 weighted image with dynamic Gd contrast (A) demonstrate hypointensive lesion $7 \times 5 \times 6 \mathrm{~mm}$. PRL level of $1164 \mathrm{ng} / \mathrm{ml}$. Endoscopic endonasal resection of microadenoma. Intraoperative images are presented (C-E). Images C, D show intraoperative endoscopic view of microprolactinoma $\left(^{*}\right)$ and pituitary gland on the left side. Image $\mathrm{E}$ shows intraoperative endoscopic view mircoprolactinoma total removal and pituitary gland $(\mathrm{Pg})$. Coronar and sagittal postoperative T1 weighted image with dynamic Gd contrast (B) after surgery. Following surgery, the patient's prolactin level returned to normal. Patient got pregnant 3 months after surgery. Catamnenis 2 years. No DA after surgery.

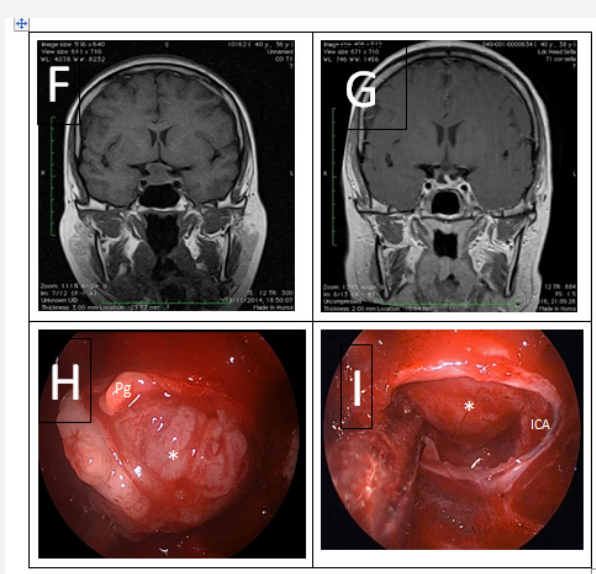

Case 2: Women 37 y.o. presenting with dysmenorrhea, galactorrhea. Preoperative T1 weighted image (F) demonstrate hypertensive

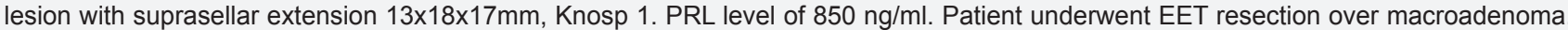
Intraoperative images are presented $(\mathrm{H}, \mathrm{I})$. Image $\mathrm{G}$ shows intraoperative endoscopic view of macroprolactinoma $\left(^{*}\right)$ and part of pituitary gland $(\mathrm{Pg})$ superiorly. Image $\mathrm{H}$ shows intraoperative endoscopic view of the macroprolactinoma total removal, diaphragm with pituitary $\left({ }^{*}\right)$ and medial wall of left cavernous internal carotid artery (ICA). Postoperative MRI with dynamic Gd contrast G showed total resection of the tumor with suprasellar cistern decompression. Prolactin level returned to normal within 3 months. Catamnenis 4 years. No DA therapy after surgery. 
$\begin{array}{ll}\text { (CC) } & \begin{array}{l}\text { This work is licensed under Creative } \\ \text { Commons Attribution 4.0 Licens } \\ \text { DOI: } 10.19080 / J E T R .2018 .03 .555622\end{array}\end{array}$

\section{Your next submission with Juniper Publishers} will reach you the below assets

- Quality Editorial service

- Swift Peer Review

- Reprints availability

- E-prints Service

- Manuscript Podcast for convenient understanding

- Global attainment for your research

- Manuscript accessibility in different formats ( Pdf, E-pub, Full Text, Audio)

- Unceasing customer service

Track the below URL for one-step submission https://juniperpublishers.com/online-submission.php 